\title{
The State of Origin of Australian Equity: Does Active Fund Manager Location Matter?
}

\author{
Kingsley Fong ${ }^{\text {a }}$, David R. Gallagher ${ }^{\text {a }}$, Adrian D. Lee ${ }^{\text {a,* }}$ \\ ${ }^{a}$ Australian School of Business, The University of New South Wales, Sydney, N.S.W. 2052, \\ Australia
}

\begin{abstract}
We examine the relation of active equity fund managers' location proximity to a stock's headquarter and fund managers' stock selection skill and investment behaviour using a representative sample of Australian institutional equity funds. Contrary to the findings of much international research, our study reveals evidence which is inconsistent with a location advantage for Melbourne and Sydney active equity funds. Both Melbourne and Sydney fund managers overweight Melbourne stocks, exhibit skill in picking Sydney stocks and avoid poor performing Melbourne and Sydney stocks. In addition, we find no evidence of word-of-mouth trading effects in Melbourne or Sydney funds. Taken together, this suggests information asymmetries arising from location are weak for Melbourne and Sydney funds.
\end{abstract}

Keywords:

Location, Information Advantages, Portfolio Management, Investment Performance

* Corresponding author: E-mail address: ad.lee@unsw.edu.au (A.D. Lee) Telephone: (+61 2) 92369101 


\section{Introduction}

Does the location of a fund manager affect the investment behavior and performance of the fund? This question is of great interest to fund managers, investors and market regulators. The question is also interesting given the important research by Coval and Moskowitz (2001) who find evidence that U.S. funds overweight and exhibit better stock selection in local stocks (within $100 \mathrm{~km}$ of the fund) than more distant stocks. The primary explanation of this phenomenon has been fund managers' informational advantages arising from their geographic proximity to the corporate headquarters of these companies. Another regularity related to a fund's location is documented by Hong, Kubik and Stein (2005) who find that funds in the same city tend to buy and sell stocks together, even if the stock is not geographically proximate. They attribute this trading behavior to information epidemically spreading through word-of-mouth. These findings help us to understand how price sensitive information is diffused in the market and are of interest to market regulators with regard to market efficiency and integrity.

This study examines whether active Australian equity funds exhibit any location advantage by analysing their portfolio holdings conditional on whether funds and corporate headquarters are located in Sydney or Melbourne. Australian equity fund managers are geographically concentrated in Melbourne and Sydney. Funds located in these two cities account for 98.9\% of funds by dollar value and approximately $92 \%$ by fund count using information from the Portfolio Analytics Database of Australian institutional fund managers during the period 1997 to $2001^{1}$. The geographic distance between these two cities is about the same distance between U.S. financial hubs of Boston and New York (approximately 1000 kilometres) where location advantage has been documented. The similarities between these U.S. and Australian cities in terms of geographic distance and financial service concentration suggests that fund managers in Melbourne and Sydney may have developed information advantages from their location. However, there are other factors which may influence the location effect in Australia: listed companies on the Australian Stock Exchange (ASX hereafter) are primarily located in

\footnotetext{
${ }^{1}$ In the Mercer database, $95 \%$ of funds by fund count are located in Sydney or Melbourne during the same period.
} 
Melbourne or Sydney ${ }^{2}$ and thus funds need only locate themselves in these two cities to benefit from any apparent location advantage.

Another notable difference between the U.S. and the Australian environment is disclosure regimes. Coval and Moskowitz (2001) find location bias in the U.S. during the pre-Regulation Fair Disclosure (hereafter F.D.) period where selective disclosure was possible. In contrast, the ASX has been adopting a continuous disclosure policy during our entire sample period. Chapter 3 of the ASX Listing Rules requires that once an entity becomes aware of any information that a reasonable person would expect it to have a material impact on its share price, the entity must immediately tell the ASX that information. The ASX then would disseminate this information in an announcement, sometimes with trading halts. While there are no studies on the effect of Regulation F.D. on the skill of fund managers, several studies look at its effects on analyst forecast accuracy and dispersion with mixed findings ${ }^{3}$. Heflin, Subramanyam and Zhang (2003) and Mohanram and Sunder (2003) find no change in analyst forecast accuracy and dispersion in the post-F.D. period. However Agrawal and Chadha (2006) find sell-side analysts have less accuracy and higher dispersion of forecasts. Also, Bailey, et al. (2003) find higher forecast dispersion and Findlay and Mathew (2006) find less accuracy in forecasts post-F.D.. This suggests at the very least, location advantages are not improved in a continuous disclosure regime.

In contrast to international research, we find weak evidence of a location effect in Australia. Funds in Melbourne and Sydney pick local stocks with higher risk-adjusted returns than local stocks not held. The effect is stronger if we consider local stocks within the fund city's central business district (CBD) than for local stocks within 100km of the fund's CBD. Both Melbourne and Sydney fund managers overweight Melbourne stocks and underweight Sydney stocks. They also both show skill in picking Sydney large capitalisation stocks and avoiding poor performing Melbourne and Sydney stocks. However, the ability to avoid poor performing stocks is positive and significant in only mid and small capitalisation stocks, and not confined to those in the

\footnotetext{
${ }^{2}$ During our sample period for S\&P/ASX 300 stocks, $84.90 \%$ of stocks by market capitalisation and $71.88 \%$ by stock count were headquartered within 100km of Melbourne's or Sydney's central business district.

${ }^{3}$ See Sidhu, Smith and Whaley (2006) for a more comprehensive literature review of studies on the effect of Regulation F.D.
} 
fund's city. This is contrary to the implication of the existence of a location advantage. Analysis by fund investment style and stocks grouped by book-to-market also show no strong evidence of location advantage. We also find no evidence of a word-of-mouth effect. Taken together, this suggests Melbourne and Sydney funds do not display similarly strong location bias as their U.S. counterparts.

Our study contributes to the literature on geography, investment management and markets by studying location effects outside of the U.S. Our analysis is also more granular as we use monthly fund holdings of Australian active funds compared to the quarterly U.S. fund holdings data. The study also provides an examination of location effects in geographically concentrated markets, which may be applicable to other countries.

The paper is structured as follows: Section 2 provides a brief literature review, Section 3 describes the datasets used, section 4 the methodology, section 5 the results and section 6 concludes the paper.

\section{Brief Literature Review}

\subsection{Home Bias}

The 'home bias' literature has garnered much attention and is well established. Early studies by French and Poterba (1991) and Cooper and Kaplanis (1994) find international equity funds domiciled in the U.S. hold 90 percent of their portfolio in U.S. stocks, when the U.S. market constitutes only 50 percent of world markets. More recent studies document a significant home bias occurring at the intra-country level. Coval and Moskowitz (1999), Coval and Moskowitz (2001) and Huberman (2001) all find that U.S. investors tend to overweight stocks (relative to market weights) geographically proximate to them.

Naturally, researchers have turned to explain why this home bias occurs. Rational explanations include market frictions such as cultural difference, foreign exchange movements and taxation 
when investing overseas ${ }^{4}$. However this would not be sufficient to explain the effect of home bias at the intra-country level. Coval and Moskowitz (2001) suggest home bias is rationally motivated by local investors having private information on local companies. They find U.S. mutual funds earn 1.18 percent higher risk-adjusted returns on stocks located within $100 \mathrm{~km}$ of a fund than on distant stocks. Indeed, Malloy (2005) finds geographically proximate analysts to a company are more accurate than distant analysts, suggesting location has private information advantages. Ivkovic and Weisbenner (2005) find U.S. individual investors earn 3.2 percent more on their local holdings than their distant holdings, while Massa and Simonov (2006) find similar evidence for a representative sample of Swedish investors. However, using the same database as Ivkovic and Weisbenner (2005) and accounting for contemporaneously correlated stock returns, Seasholes and Zhu (2005) document no evidence of private information of local investors. Grinblatt and Keloharju (2000) also find domestic investors in Finland underperform foreign investors, contradicting the private information hypothesis. Given these studies, it is very interesting to investigate whether there is any significant benefit to institutional investors locating in either of Australia's largest financial capitals. Attention to this area of research is of further importance given the inconsistent evidence of prior studies with respect to geography and stock returns.

An alternative explanation of home bias is that it is a result of investors trading stocks based on familiarity. Given this hypothesis, geographic distance is one of many factors influencing an investor to hold a stock. Grinblatt and Keloharju (2001) find Finnish investors tend to hold firms that communicate in the same language and have a chief executive with the same cultural background as the investor, in addition to being located closely. In addition they find the effects are stronger for households than for 'investment-savvy' institutions. Consistent with the familiarity hypothesis, Zhu (2003) finds individual U.S. investors tend to invest in remote companies that spend heavily on advertising. In an examination of the Regional Bell Operating Company share registry, Huberman (2001) finds shareholders tend to live in the area in which it operates or they are former employees of the company. Indeed the literature shows familiarity is more applicable to individual investor home bias than to institutional investors.

\footnotetext{
${ }^{4}$ Coval and Moskowitz (1999) provide a brief summary of cross-border influences affecting home-bias.
} 


\subsection{Heterogeneous Investors by Location and Word-Of-Mouth Effects}

The word-of-mouth effect literature focuses on the influence of geographically proximate investors (e.g. investors in the same city) on each other. The literature may be interpreted as an offshoot to other literature dealing with the heterogeneity of investors across geographic regions. At the country level, there is evidence of foreign and domestic investors behaving differently. Hau (2001) finds on the German Xetra, traders in non-German-speaking cities generate lower trading profits compared to their German-speaking counterparts. Grinblatt and Keloharju (2000) find on the Finnish stock exchange that foreign investors tend to be momentum traders, while domestic investors tend to be contrarian. Similarly Choe, Kho and Stulz (2005) find that on the Korean stock exchange, foreign funds trade on intra-day momentum, to their detriment, and consequently pay more than domestic funds when they buy, and receive less when they sell, for both medium and large trades.

In addition, there is evidence of heterogeneous investors across cities, with homogeneity within a city. Hong, Kubik and Stein (2005) show U.S. mutual funds within the same city tend to buy and sell the same stock at the same time regardless of the stock's location. This is consistent with the word-of-mouth occurring initially at the city level. Feng and Seasholes (2004) find significant correlated trading for individual investors in China within cities, and negative correlated trading between cities. They find this is consistent with a simple model of heterogeneously informed investors, where distance affects the precision of public news announcements. This results in one group in a city buying, and the other city's investors selling. In comparison, our study examines whether such heterogeneity exists for Australian funds, in particular whether Melbourne funds exhibit different trading behaviour to Sydney funds.

\section{Data}

We use month-end portfolio holdings data from the Portfolio Analytics Database (PAD). This database comprises the holdings of 38 active Australian wholesale equity fund managers (PAD funds hereafter). It also contains information on the location of the fund, whether it is a boutique or one of the top 15 largest domestic equity firms and its investment style (GARP (Growth at a 
reasonable price), Growth, Style-Neutral, Value and Other). Further details of this database are detailed in Gallagher and Looi (2006). Our sample period is from January 1997 to December 2001. Table 1 Panel A reports the number of funds located in Melbourne and Sydney. 'Other'

funds are located in other major cities but for confidentiality reasons we do not disclose the city to help preserve anonymity. The majority of active funds are in Sydney, with 27 funds from 22 fund families located there.

To ensure the PAD sample is representative of the population of active funds, we compare the PAD database to the Mercer database, which contains the monthly before fee actual returns of Australian active funds. We calculate the raw return and return difference of the equally weighted average manager in PAD and in the Mercer database during the sample period by fund city. Table 1 Panel B reports our results. We find that while PAD fund managers by city have higher returns than the respective Mercer sample, these differences are not statistically significant. This suggests the PAD sample is representative of the active fund population.

\section{[INSERT TABLE 1]}

Monthly dilution-adjusted share returns, month-end market capitalisation and stock ASX industry classification data are sourced from the AGSM Share Price and Price Relative (SPPR) database. Monthly returns of the S\&P/ASX 300 Accumulation Index are sourced from SIRCA. The Aspect Financial database is used for financial year end book value (Aspect item ID 7010) and also for the headquarter city, suburb and postcode of each stock. Month-end weight compositions of the S\&P/ASX 300 are sourced from Vanguard Investments Australia. We also use the Geoscience Australia database (http://www.ga.gov.au/map/names/) to collect longitude and latitude coordinates for each location. Where possible, we use the 'official' coordinates.

\section{Methodology}

\subsection{Risk-adjusted Returns}


We follow the methodology of Fong, Gallagher and Lee (2007) to calculate risk-adjusted (alpha) returns (which is a variation on the Daniel, et al. (1997) measure). In the FGL (2007) study, each stock in the S\&P/ASX 300 is matched to a portfolio of stocks with similar size, book-to-market and momentum characteristics. The risk-adjusted return is the raw return of the stock less the index-weighted return of its matching portfolio. Mathematically this is:

$$
C S_{t}=\sum_{i=1}^{N} w_{i, t-1}\left(R_{i, t}-R_{t}^{b i, t-1}\right)
$$

Where $w_{i, t-1}$ is the weight of stock $i$ in month $t-1, R_{i, t}$ is the monthly return of stock $i$ in month $t$, $R_{t}^{b i t-1}$ is the monthly return of the matching characteristic benchmark portfolio to stock $i$ at month $t-1$ in month $t$.

\subsection{Geographic Distance Calculation}

To calculate the distance between two locations we use the great distance circle method ${ }^{5}$ calculated (in kilometres) as:

$$
\begin{aligned}
& \text { Dist. }=1.852 * 60 * \operatorname{arcos}\left(\sin \left(\text { lat }_{1}\right) * \sin \left(\text { lat }_{2}\right)\right. \\
& \left.+\cos \left(\text { lat }_{1}\right) * \cos \left(\text { lat }_{2}\right) * \cos *\left(\text { lon }_{2}-\text { lat }_{1}\right)\right)
\end{aligned}
$$

Where $l t_{1}$ and $\operatorname{lon}_{1}$ are the latitude and longitude coordinates of the first location, lat 2 and $\operatorname{lon}_{2}$ for the second location. All coordinates are in radians.

\subsection{Word-of-Mouth Effect}

To measure the effect of local peers on a fund, we follow Hong, Kubik and Stein (2005) to calculate whether a word-of-mouth effect exists in Melbourne and Sydney. The model is:

$$
\Delta h_{j, k, l, t}^{i}=\alpha_{c} \Delta H_{c, x k, t}^{i}+\beta_{c} * \Delta H_{c, t}^{i}+\gamma_{c} * \Delta H_{r, t}^{i}+\varepsilon_{j, k, l, t}^{i}
$$

\footnotetext{
${ }^{5}$ More detail of this method can be found at the Geoscience Australia website: http://www.ga.gov.au/geodesy/datums/distance.jsp\#circle
} 
Where $\Delta h_{j, k, l, t}^{i}$ is the change in holdings of fund $j$ in family $k$ for stock $i$ in time $t$. This is calculated as:

$$
\Delta h_{j, k, l, t}^{i}=\frac{\left(N o S_{j, i, t} / \operatorname{SplitF}_{j, i, t}-N o S_{j, i, t-1}\right) * P_{t-1}}{\sum_{i=1}^{m} \operatorname{NoS}_{j, i, t-1} * P_{t-1}}
$$

Where $N o S_{j, i, t}$ is the number of shares held in stock $i$ by fund $j, S p l i t F_{j, I, \mathrm{t}}$ is the split factor of the stock in month $t$ and $P_{t-1}$ is the one month lagged share price. The use of only lagged share prices fixes the price effect allowing only for changes in the number of shares to infer trading. $\Delta H_{c, x k, t}^{i}$ is the change in holdings of all funds in the same city except those funds in family $k$ and $\Delta H_{c, t}^{i}$ is the equally weighted average change of the share of funds' portfolio invested in stock $i$ in month $t$ of all funds in the other major city (Melbourne/Sydney). $\Delta H_{r, t}^{i}$ is the equally weighted change for the funds not in Melbourne or Sydney. Following Hong, Kubik and Stein (2005), we estimate OLS coefficients for the model by fund city and stock city. A stock is located in a city if it is within $1 \mathrm{~km}$ of its CBD. We also estimate a version of the model incorporating three lags for each independent variable.

The intuition of the model is that a word-of-mouth effect exists if the coefficient of the own-city variable, $\Delta H_{c, x k, t}^{i}$ is positive and significantly different to the other two coefficients for other-city effects, $\beta_{c}$ and $\gamma_{c}$. This would thus imply a fund's trade is more influenced by fund trades in the same city than funds in other cities. To measure whether this difference is statistically significant, we perform an $F$-test on the null hypothesis that the difference of $\alpha_{c}$ to $\beta_{c}$ and $\gamma_{c}$ is not different to zero.

\section{Results}

\subsection{Descriptive Statistics}

We first examine the overall value-weighted alpha performance of Melbourne and Sydney funds across all stocks, and the returns of stocks located in Melbourne and Sydney. Table 1 Panel A 
reports basic performance and descriptive statistics for Melbourne and Sydney funds. Sydney funds earn the highest alpha of $1.28 \%$ per year (significant at the 5\% level). This alpha is $0.35 \%$ higher than Melbourne funds and $0.3 \%$ higher than other city funds, although this difference is not statistically significant.

Table 1 Panel $\mathrm{C}$ reports the average value-weighted alpha, raw returns and market (S\&P/ASX 300) weights of stocks located in Melbourne, Sydney and elsewhere. Following Coval and Moskowitz (2001), we define a stock as located in one of the cities if it is within $100 \mathrm{~km}$ of it. For each city, stocks are placed into value-weighted portfolios and their raw and risk-adjusted returns calculated. While Sydney stocks have higher alpha than Melbourne and other stocks, this difference is not statistically significant. The difference in returns of Melbourne and Other, Sydney and Other stocks is also insignificant. This suggests stocks located in a particular city do not have higher risk-adjusted returns.

\subsection{Fund Performance in Local Stocks}

To test whether Melbourne and Sydney funds display ability in picking local stocks, we measure the value-weighted alpha of local (AlphaL) and distant stocks (AlphaD) held by city funds and the difference $(\Delta \mathrm{AlphaL})$. We also calculate the fund weight in local stocks (WeightL), the S\&P/ASX 300 weights in local stocks and the weight difference ( $\Delta$ WeightL). To measure the ability of funds to avoid poor performing local stocks, we measure $\Delta$ Not HeldL as the fund alpha in local stocks minus the value-weighted alpha of local stocks not held. Table 2 reports our findings. Panel A uses the standard definition of a local stock being within $100 \mathrm{~km}$ of the fund's city. In Panel B we define a local stock as being within $1 \mathrm{~km}$ of the city (i.e. within the fund city's CBD).

The evidence of a location effect is weak. For both definitions of local stocks in Table 2 Panels A and B, funds do not show statistically significant ability to pick local stocks over distant stocks as evident in the $\Delta \mathrm{AlphaL}$ column. While Melbourne funds overweight in Melbourne stocks by $6.1 \%$ per year $(8.84 \%$ using the $1 \mathrm{~km}$ definition in Panel B), Sydney funds underweight Sydney stocks by $-0.83 \%(-3.2 \%)$, inconsistent with a local bias. 
Restricting to the $1 \mathrm{~km}$ definition, however, pooled Melbourne and Sydney funds earn significant alpha of $3.47 \%$ per year in local stocks. Also, $\Delta$ Not HeldL, the alpha difference of local stocks held minus local stocks not held is significant and highly positive for both fund cities $(8.03 \%$ per year in Melbourne and 21.50\% in Sydney). This suggests a location advantage exists in avoiding poor performing local stocks.

[INSERT TABLE 2]

\subsection{Fund Performance and Local Bias}

In consideration of whether the location effect is stronger in funds that overweight in local stocks, every month, we rank funds into three groups based on their fund weight in local stocks less the market index weight, and repeat the above experiment using the $1 \mathrm{~km}$ definition. We report our results in Table 3. In contrast to Coval and Moskowitz (2001) we find funds which are most overweight in local stocks (Local Rank = 3) underperform the other two fund groups, although the return difference is not statistically significant. Similarly, the return difference of stocks held and not held by local, high overweight funds is lower than the other two groups.

\section{[INSERT TABLE 3]}

To understand why our results differ to Coval and Moskowitz (2001), we consider a partition of the performance of Melbourne and Sydney funds by stock location. For comparative purposes we also include funds elsewhere ('Other'). Table 4 reports our results, where city stocks are defined as being within $1 \mathrm{~km}$ of the city. Stocks not in Melbourne or Sydney are grouped into 'Other' stocks. Surprisingly, we find Sydney funds are 3.28\% overweight in Melbourne stocks. In unreported results, we investigate whether this is due to the largest Melbourne stocks (by market capitalisation) being held by Sydney funds for index tracking reasons. Removing the largest five Melbourne stocks, we find Sydney funds remain overweight in Melbourne and underweight Sydney stocks. 


\section{[INSERT TABLE 4]}

Both Melbourne and Sydney funds show statistically significant and positive ability in picking Sydney stocks, despite both underweighting Sydney stocks. Melbourne funds earn 3.99\% alpha in Melbourne stocks (5\% significant) while Sydney funds earn 3.66\% (10\% significant). Interestingly, while Other funds show no skill in picking stocks in Sydney or Melbourne, they underweight stocks in those cities and overweight in Other stocks suggesting a degree of local bias. The risk-adjusted return difference of stocks held less stocks not held in a city is strongly positive for Melbourne and Sydney funds in Melbourne and Sydney stocks, but not for Other stocks. This suggests Melbourne and Sydney funds appear to have similar location skill properties.

\subsection{City Fund Performance by Stock Size and Stock City}

While the evidence so far does not appear to point towards the presence of location advantages, this section examines whether funds show selection skill by stock size and stock location. The intuition is that funds in one city should have location advantages in picking small stocks that have lower levels of analyst coverage and are also proximate to them. Every month, stocks in the S\&P/ASX 300 held by funds in each city are sorted by stock location (Melbourne, Sydney or Other) and by size which consists of three groups: 'Large Cap' for the largest 50 stocks by index weight, 'Mid Cap' for stocks from 51-100 and 'Small Cap' for the remainder. These size groupings are closely related to the ASX stock size definitions. The average fund weight in excess of the market weight, alpha and difference of alpha less alpha of stocks not held for each city/size group are reported in Table 5 in Panel A, B and C respectively.

\section{[INSERT TABLE 5]}

Melbourne and Sydney funds underweight Small Cap stocks regardless of location as shown in Panel A. Melbourne funds underweight Melbourne Small Cap stocks by $-0.84 \%$ while Sydney underweight Sydney Small Cap by $-1.24 \%$, both statistically significant. In Panel B, Melbourne and Sydney funds do not show evidence of picking Small Cap stocks in their own respective 
cities or elsewhere. Interestingly, Melbourne funds earn 10\% significant alpha of 3.65\% per year in Sydney Large Cap stocks. Sydney funds also earn 5\% significant alpha in Large Cap Sydney stocks of $4.78 \%$ per year despite underweighting these stocks by $-0.81 \%$. In Panel $\mathrm{C}$, where we measure the difference of alpha of stocks held and of stocks not held by city/size group, both Melbourne and Sydney funds display evidence of avoiding poor performing Small Cap stocks. Melbourne funds show significance of avoiding Other Small Cap (21.00\% per year), Sydney Small Cap (19.04\%) and Sydney Mid Cap (13.12\%) stocks, while Sydney funds show statistically significant ability of $22.44 \%$ per year in Melbourne Small Cap stocks. As Melbourne and Sydney funds do not show significant ability to avoid Mid and Small Cap stocks in their own cities, this is inconsistent to the presence of a location advantage.

\subsection{Location Bias by Style}

This section examines whether a location bias occurs across styles. Coval and Moskowitz (1999) argue funds with set investment objectives, such as sector funds, cannot possibly exhibit location bias if the majority of stocks they specialise in are located away from the fund. Every month, we sort funds by investment objective (GARP, Growth, Style-Neutral and Value) and then sort each fund's stocks into book-to-market quintiles. The stocks are further sorted by whether they are local (within $1 \mathrm{~km}$ of the fund city) or distant. In the case of home bias occurring, we would expect funds to overweight in local stocks more than in distant stocks matching its investment objective (e.g. low book-to-market stocks for growth funds). Also, funds are expected to have higher alpha in held local stocks than in held distant stocks that fit their investment style. In addition, the alpha of held local stocks less not held local stocks should be higher than the alpha of held distant stocks less not held distant stocks matching its investment style. In other words, funds should have better ability to avoid poor performing local stocks than poor performing distant stocks matching its investment style. Every month, stocks are sorted into five groups by book-to-market ratio. BM Group 1 represents the group of stocks with the lowest book-to-market ratio (growth stocks) and Group 5 the highest (value stocks). A stock is a local stock if it is located $1 \mathrm{~km}$ to the fund's city. $\triangle \mathrm{AlphaL}$ is the alpha of local stocks less the alpha of distant stocks held in the BM Group. $\Delta$ Not HeldL is the alpha of local stocks held less the valueweighted alpha of local stocks not held in the BM group. $\Delta$ WeightL is the fund weight in local 
stocks less the market weight of local stocks in that particular BM group. $\Delta \Delta$ Weight is the difference of $\Delta \mathrm{WeightL}$ and the fund weight in distant stocks less the market weight of distant stocks in that BM group. $\Delta \Delta$ Not Held is the difference of $\Delta$ Not HeldL and $\Delta$ Not HeldD, the alpha of distant stocks held less the value-weighted alpha of distant stocks not held, in the BM group. This measure tests whether a fund is able to avoid local stocks better than distant stocks with similar book-to-market. A positive measure of $\Delta \Delta$ Not Held would signify such ability.

Table 6 reports time series value-weighted fund average annualised performance and weighting measures by city and fund style and by stock's book-to-market ratio. The findings are inconsistent with the existence of location bias. The absence of statistically significant positive $\Delta$ AlphaL, except at very weak significance, shows funds do not have particularly higher skill in selecting local stocks than in distant stocks. Melbourne funds however, are better at avoiding poor performing local stocks than distant poor performing local stocks matching their investment style. This is shown by the highly positive and significant $\Delta \Delta$ Not Held for all Melbourne styles in the extreme growth stock group (BM 1). In BM 2, Melbourne managers all have statistically significant $\Delta \Delta$ Not Held. However Melbourne GARP is significant and negative suggesting these managers have better skill in avoiding poor performing distant than local moderate growth stocks, contrary to a location advantage. In Sydney, the results for $\Delta \Delta$ Not Held generally point against a location effect. Growth funds show positive and significant $\Delta \Delta$ Not Held in BM 2 stocks which appears consistent to displaying location advantages by fund style. However at the same time, Growth funds show negative though insignificant $\Delta \Delta$ Not Held for extreme growth stocks (BM 1). GARP funds show negative and insignificant $\Delta \Delta$ Not Held in growth stocks (BM 1 and BM 2), while Value funds show negative $\Delta \Delta$ Not Held in value stock groups (significant for BM 4 and insignificant for BM 5). Sydney Style Neutral funds show positive and significant $\Delta \Delta$ Not Held in BM3 stocks however are negative in BM 1 and BM 5 stocks. In the fund weight measure, $\Delta$ WeightL, only Melbourne Style Neutral shows significant overweight in BM 1 local stocks than distant stocks consistent to its fund objectives. The findings suggest that fund managers' local bias does not exist with respect to investment style.

[INSERT TABLE 6] 


\subsection{Location Bias within Industries}

This section looks at whether location bias exists within industry: funds may bias in industries concentrated in their own cities ${ }^{6}$. Since Melbourne and Sydney are Australia's largest financial centres, it would be appropriate to look at financial stocks. To classify stocks, we use ASX Classification Industry Codes from the AGSM SPPR database. Our tests look at stocks with industry codes 16 (Banking and Finance) and 19 (Financial Services). We then run similar tests as in Section 5.5 except for the test measures for avoiding poor stocks ( $\Delta$ Not Held and $\Delta \Delta$ Not Held), as nearly all stocks in these industries are held by at least one fund in a fund city.

Table 7 reports average performance and weighting measures by fund city and industry code. For comparison, we also calculate measures for Other funds, where a stock is considered local if it is not located within $1 \mathrm{~km}$ of Sydney or Melbourne's CBD. Other and Sydney funds earn positive and significant alpha in local stocks (AlphaL) in Banking and Finance and Other funds also select well in Financial Services stock. However the corresponding statistically insignificant $\triangle$ AlphaL suggests there is no difference in skill to choosing distant stocks in the same industry. While Melbourne funds weight more in local financial stocks than in distant stocks, as indicated by the positive and significant $\Delta \Delta$ Weight measure, they do not show particular significant stock picking skill. Therefore Melbourne and Sydney funds do not show evidence of both higher skills in picking local stocks in the cities' specialised industry and higher weighting towards these stocks.

\section{[INSERT TABLE 7]}

\subsection{Word-Of-Mouth Effects within Cities}

Table 8 reports the OLS coefficient and $F$-Tests for coefficient differences in equation 4. Panel A reports for the model without lags, while Panel B reports for the model with three lags. The Panel A coefficient estimates are positive and statistically significant for nearly all independent variables suggesting a high degree of correlated trading regardless of location. This is consistent

\footnotetext{
${ }^{6}$ We thank the referee for suggesting this idea. It would be even more powerful to test the location advantage of, for example, a mining fund in Perth since many mining firms are headquartered there. However, our sample consists of large institutional equity funds only and none of them are located in Perth. Therefore, we focus on banking and financial services stocks here.
} 
with former evidence of Melbourne and Sydney funds having similar weighting and performance attributes.

For a word-of-mouth effect to be evident, we expect the $F$-Test of own-city minus other city coefficients to be positive and statistically different to zero. This test is shown in the 'OwnOther' column of Panel A and B. Contrary to a word-of-mouth effect, the coefficient is negative and statistically significant for Melbourne funds regardless of stock location, and for Sydney funds in Other stocks. There appears to be no influence either way for Sydney funds in Melbourne or Sydney stocks. The results are robust using the no-lags and lags model. This suggests Melbourne funds in particular are more influenced by funds in Sydney and elsewhere, rather than funds within Melbourne.

\section{[INSERT TABLE 8]}

In Panel B, we also test whether there is a lagged influence. We test whether the once lagged own city effect coefficient, $\alpha_{c, t-1}$ is statistically different to the other lagged coefficients, $\beta_{c, t-1}$ and $\gamma_{c, t-1}$. This test is shown in the 'Own-Other 1 Lag' column. We also report the difference for all three lags in the 'Own-Other 3 Lags' column. Sydney funds in Melbourne stocks appear to be more influenced by the lagged trades of other Sydney funds than funds in other cities. The 1\% statistically significant one-lag difference measure of 0.1645 suggests a Sydney fund in a Melbourne stock will increase (decrease) its holdings in a stock $0.1645 \%$ more than a fund located in another city, in response to the last month's increase (decrease) by other Sydney funds. This measure is robust when considering three lags. For all other funds and cities, however, the lagged differences are mainly positive, however not statistically significant. In comparison to the results reported by Hong, Kubik and Stein (2005), evidence of a word-ofmouth effect is very weak in Australia.

\section{Conclusion}

The literature has identified geographic location as a highly influential factor in ownership behaviour and portfolio performance of stocks by investors. In the Australian setting, we find 
only weak evidence of a location effect for Melbourne and Sydney active equity funds investing in S\&P/ASX 300 stocks. Melbourne and Sydney funds show similar portfolio weighting and stock selection skill in Melbourne and Sydney stocks, overweight Melbourne and underweight Sydney stocks. No particular location bias is found when stocks are sorted by size, and also when funds are grouped by city/fund style and stocks sorted by book-to-market to control for fund objective. This suggests Melbourne and Sydney funds have very similar location biases, and thus are very much alike in terms of their trading strategies across S\&P/ASX 300 stocks. The weak evidence of a location effect is further reinforced given the absence of an intra-city word-ofmouth effect. Rather, positively correlated trading appears to exist in both cities. Taken together, this suggests information asymmetries with respect to location is weak for Melbourne and Sydney funds.

Our analysis of location effects in the Australian context, while comprehensive in showing the lack of location bias in our representative sample of Australian institutional funds, is by no means a rebuttal of existing international evidence. The fairly recent sample period we use from 1997 to 2001, represents a time where the cost and speed of trading and communication for Australian fund managers have improved markedly. The reduction in such market frictions may explanation the absence of location effects in our study ${ }^{7}$. Future research could use earlier sample periods of Australian fund data, such as that of Pinnuck (2003) to test this hypothesis.

\section{References}

Agrawal, A. \& S. Chadha 2006, 'Who is afraid of Reg FD? The behavior and performance of sell-side analysts following the SEC's fair disclosure rules', Journal of Business, vol. 79, no. 6, pp. 2811-34.

Bailey, W., H. Li, C.X. Mao, \& R. Zhong 2003, 'Regulation fair disclosure and earnings information: Market, analyst, and corporate responses', The Journal of Finance, vol. 58, no. 6, pp. 2487-514.

Choe, H., B.C. Kho, \& R.M. Stulz 2005, 'Do domestic investors have an edge? The trading experience of foreign investors in Korea', Review of Financial Studies, vol. 18, no. 3, pp. 795-829.

Cooper, I. \& E. Kaplanis 1994, 'Home bias in equity portfolios, inflation hedging, and international capital market equilibrium', Review of Financial Studies, vol. 7, no. 1, pp. 45-60.

\footnotetext{
${ }^{7}$ Indeed Coval and Moskowitz (2001) Table 1 show the location bias of U.S. funds is much weaker in the latter half of their sample period (1985-1994) which would support such a hypothesis.
} 
Coval, J.D. \& T.J. Moskowitz 1999, 'Home bias at home: Local equity preference in domestic portfolios', The Journal of Finance, vol. 54, no. 6, pp. 2045-73.

Coval, J.D. \& T.J. Moskowitz 2001, 'The geography of investment: Informed trading and asset prices', Journal of Political Economy, vol. 109, no. pp. 811-41.

Daniel, K., M. Grinblatt, S. Titman, \& R. Wermers 1997, 'Measuring mutual fund performance with characteristic-based benchmarks', Journal of Finance, vol. 52, no. 3, pp. 1035-58.

Feng, L.E.I. \& M.S. Seasholes 2004, 'Correlated trading and location', Journal of Finance, vol. 59, no. 5, pp. 2117-44.

Findlay, S. \& P.G. Mathew 2006, 'An examination of the differential impact of regulation FD on analysts' forecast accuracy', Financial Review, vol. 41, no. 1, pp. 9-31.

Fong, K.Y., D.R. Gallagher, \& A.D. Lee 2007, 'Measuring characteristic selectivity and timing ability using equity portfolio holdings', Working Paper, University of New South Wales.

French, K. \& J. Poterba 1991, 'International diversification and international equity markets', American Economic Review, vol. 81, no. 2, pp. 222-26.

Gallagher, D.R. \& A. Looi 2006, 'Trading behaviour and the performance of daily institutional trades', Accounting and Finance, vol. 46, no. 1, pp. 125-47.

Grinblatt, M. \& M. Keloharju 2000, 'The investment behavior and performance of various investor types: A study of Finland's unique data set', Journal of Financial Economics, vol. 55 , no. 1, pp. 43-67.

Grinblatt, M. \& M. Keloharju 2001, 'How distance, language, and culture influence stockholdings and trades', The Journal of Finance, vol. 56, no. 3, pp. 1053-73.

Hau, H. 2001, 'Location matters: An examination of trading profits', Journal of Finance, vol. 56, no. 5, pp. 1959-83.

Heflin, F., K.R. Subramanyam, \& Y. Zhang 2003, 'Regulation FD and the financial information environment: Early evidence', The Accounting Review, vol. 78, no. 1, pp. 1-37.

Hong, H., J.D. Kubik, \& J.C. Stein 2005, 'Thy neighbor's portfolio: Word-of-mouth effects in the holdings and trades of money managers', Journal of Finance, vol. 60, no. pp. 2801-24.

Huberman, G. 2001, 'Familiarity breeds investment', Review of Financial Studies, vol. 14, no. 3, pp. $659-80$.

Ivkovic, Z. \& S. Weisbenner 2005, 'Local does as local is: Information content of the geography of individual investors' common stock investments', Journal of Finance, vol. 60, no. 1, pp. 267-306.

Malloy, C.J. 2005, 'The geography of equity analysis', Journal of Finance, vol. 60, no. 2, pp. 719-55.

Massa, M. \& A. Simonov 2006, 'Hedging, familiarity and portfolio choice', Review of Financial Studies, vol. 19, no. 2, pp. 633.

Mohanram, P.S. \& S.V. Sunder 2003, 'How has regulation fair disclosure affected the functioning of financial analysts?' Working Paper, Columbia Business School.

Pinnuck, M. 2003, 'An examination of the performance of the trades and stock holdings of fund managers: Further evidence', Journal of Financial \& Quantitative Analysis, vol. 38, no. 4, pp. 811-28.

Seasholes, M.S. \& N. Zhu 2005, 'Is there information in the local portfolio choices of individuals?' Working Paper, U.C. Berkeley.

Sidhu, B.K., T.M. Smith, \& R.E. Whaley 2006, 'Regulation fair disclosure and the cost of adverse selection', Working Paper, Australian Graduate School of Management, University of New South Wales. 
Zhu, N. 2003, 'The local bias of individual investors', Working Paper, Yale University. 


\section{Table 1}

\section{Descriptive Statistics}

Table reports annualised average monthly returns for funds in the PAD database by fund city and stock headquarter city over the period 1997-2001. At stock city level, only S\&P/ASX 300 constituent stocks are considered. A stock is located in a city if its headquarters is within $100 \mathrm{~km}$ of it. Alpha is the risk-adjusted return computed using the methodology of Fong, Gallagher and Lee (2007). Panel A reports the value-weighted alpha and raw return of Melbourne and Sydney funds. Panel B reports the average equal-weighted fund raw return and return difference of funds in the PAD database and Mercer database by fund city. Panel $\mathrm{C}$ reports the average risk-adjusted, raw return, and S\&P/ASX 300 weight of stocks located in Melbourne or Sydney. A stock is located as in the city if it is within $100 \mathrm{~km}$ of it. T-statistics are in parenthesis. ${ }^{* * *}, * * *$ denotes statistical significance at the 1,5 and $10 \%$ level.

\begin{tabular}{|c|c|c|c|c|c|c|c|}
\hline \multicolumn{8}{|c|}{ Panel A. Performance of Funds by City in PAD Database } \\
\hline Fund City & \multicolumn{2}{|c|}{ No. Fund Families } & No. Funds & Alpha & $\mathrm{T}$ & Raw & $\mathrm{T}$ \\
\hline Melbourne & \multicolumn{2}{|c|}{7} & 8 & 0.93 & $(1.40)$ & $13.68 * *$ & $(2.23)$ \\
\hline Other & \multicolumn{2}{|l|}{2} & 3 & 0.98 & $(1.18)$ & $13.07 * *$ & $(2.19)$ \\
\hline Sydney & \multirow{4}{*}{\multicolumn{2}{|c|}{22}} & 27 & $1.28 * *$ & $(2.32)$ & $13.98 * *$ & $(2.32)$ \\
\hline Melb. - Oth. & & & & -0.06 & $(-0.07)$ & 0.61 & $(0.52)$ \\
\hline Syd. - Oth. & & & & 0.30 & $(0.33)$ & 0.91 & $(0.84)$ \\
\hline Syd. - Melb. & & & & 0.35 & $(0.52)$ & 0.30 & $(0.38)$ \\
\hline \multicolumn{8}{|c|}{ Panel B. Equal Weighted PAD and Mercer Raw Returns } \\
\hline Fund City & $\begin{array}{l}\text { PAD Raw } \\
\text { Return }\end{array}$ & $\mathrm{T}$ & $\begin{array}{c}\text { Mercer Raw } \\
\text { Return }\end{array}$ & $\mathrm{T}$ & \multicolumn{2}{|c|}{ PAD - Mercer } & $\mathrm{T}$ \\
\hline Melbourne & $13.45^{* *}$ & $(2.23)$ & $12.80 * *$ & $(2.20)$ & \multicolumn{2}{|c|}{0.64} & $(0.07)$ \\
\hline Other & $13.04 * *$ & $(2.19)$ & $12.98 * *$ & $(2.29)$ & \multicolumn{2}{|c|}{0.06} & $(0.01)$ \\
\hline Sydney & $14.47 * *$ & $(2.43)$ & $13.79 * *$ & $(2.39)$ & \multicolumn{2}{|c|}{0.68} & $(0.07)$ \\
\hline Melb. - Oth. & 0.40 & $(0.38)$ & -0.18 & $(-0.22)$ & \multicolumn{2}{|c|}{0.58} & $(0.44)$ \\
\hline Syd. - Oth. & 1.43 & $(1.50)$ & 0.81 & $(0.85)$ & \multicolumn{2}{|c|}{0.62} & $(0.47)$ \\
\hline Syd. - Melb. & 1.03 & $(1.40)$ & 0.99 & $(1.55)$ & \multicolumn{2}{|c|}{0.04} & $(0.04)$ \\
\hline All & $14.21 * *$ & $(2.38)$ & $13.50 * *$ & $(2.34)$ & \multicolumn{2}{|c|}{0.71} & $(0.08)$ \\
\hline \multicolumn{8}{|c|}{ Panel C. Performance of Stocks by City } \\
\hline Stock City & Alpha & $\mathrm{T}$ & Raw & $\mathrm{T}$ & \multicolumn{3}{|c|}{ Market Weight (\%) } \\
\hline Melbourne & 0.25 & $(0.17)$ & 11.16 & $(1.64)$ & \multicolumn{3}{|c|}{40.42} \\
\hline Other & -1.35 & $(-0.44)$ & 7.74 & (1.09) & \multicolumn{3}{|c|}{15.10} \\
\hline Sydney & 1.11 & $(0.65)$ & $14.12 * *$ & $(2.50)$ & \multicolumn{3}{|c|}{44.48} \\
\hline Melb. - Oth. & 1.60 & $(0.44)$ & 3.42 & $(0.72)$ & & & \\
\hline Syd. - Oth. & 2.46 & $(0.59)$ & 6.36 & (1.21) & & & \\
\hline Syd. - Melb. & 0.86 & $(0.30)$ & 2.96 & $(0.86)$ & & & \\
\hline
\end{tabular}




\section{Table 2}

\section{Performance of Funds in Local Stocks}

Every month, the total stock holdings of funds located in Melbourne or Sydney are grouped by whether they are within the fund's city (local) or not (distant). The table reports the average riskadjusted return using the methodology of Fong, Gallagher and Lee (2007) of local ( $\Delta$ AlphaL), distant stocks $\triangle \mathrm{AlphaD}$ and the return difference $\Delta \mathrm{AlphaL}$, fund weight in local stocks (WeightL), market weight (M. Weight) and the weight difference ( $\Delta$ WeightL), value-weighted risk-adjusted returns of local stocks not held by funds (Not HeldL) and its difference ( $\Delta$ Not HeldL) to the fund's locally held return. Panel A defines a stock as local if it is within $100 \mathrm{~km}$ of the fund's city centre, Panel B if it is $1 \mathrm{~km}$ of the fund's city centre. T-statistics are in parenthesis. $* * *, * *, *$ denotes statistical significance at the 1,5 and $10 \%$ level.

\begin{tabular}{|c|c|c|c|c|c|c|c|c|}
\hline \multicolumn{9}{|c|}{ Panel A. 100km From Radius } \\
\hline Fund City & AlphaL & AlphaD & $\Delta$ AlphaL & $\begin{array}{c}\text { WeightL } \\
(\%)\end{array}$ & $\begin{array}{c}\text { M. } \\
\text { Weight } \\
(\%)\end{array}$ & $\Delta$ WeightL & Not HeldL & $\begin{array}{l}\Delta \text { Not } \\
\text { HeldL }\end{array}$ \\
\hline \multirow[t]{2}{*}{ Melbourne } & 0.88 & 0.95 & -0.07 & \multirow[t]{2}{*}{46.52} & \multirow[t]{2}{*}{40.42} & $6.10 * * *$ & -0.47 & 1.34 \\
\hline & $(0.51)$ & $(0.72)$ & $(-0.03)$ & & & $(13.97)$ & $(-0.14)$ & $(0.35)$ \\
\hline \multirow[t]{2}{*}{ Sydney } & 2.05 & 0.84 & 1.21 & \multirow[t]{2}{*}{43.58} & \multirow[t]{2}{*}{44.40} & $-0.83 * * *$ & $-10.89 *$ & $12.94 * *$ \\
\hline & $(1.34)$ & $(0.59)$ & $(0.44)$ & & & $(-3.33)$ & $(-1.82)$ & $(2.04)$ \\
\hline \multirow[t]{2}{*}{ All } & 1.98 & 0.85 & 1.13 & \multirow[t]{2}{*}{45.05} & \multirow[t]{2}{*}{42.41} & $2.64 * * *$ & $-10.60 * *$ & $12.58 * *$ \\
\hline & $(1.43)$ & $(0.64)$ & $(0.45)$ & & & $(8.38)$ & $(-2.25)$ & $(2.52)$ \\
\hline \multicolumn{9}{|c|}{ Panel B. 1km From Radius } \\
\hline Fund City & AlphaL & AlphaD & $\Delta$ AlphaL & $\begin{array}{c}\text { WeightL } \\
(\%)\end{array}$ & $\begin{array}{c}\text { M. } \\
\text { Weight } \\
(\%)\end{array}$ & $\Delta$ WeightL & Not HeldL & $\begin{array}{l}\Delta \text { Not } \\
\text { HeldL }\end{array}$ \\
\hline \multirow[t]{2}{*}{ Melbourne } & 1.47 & 0.55 & 0.92 & \multirow[t]{2}{*}{43.54} & \multirow[t]{2}{*}{34.70} & $8.84 * * *$ & $-6.56 * *$ & $8.03 * *$ \\
\hline & $(0.78)$ & $(0.44)$ & $(0.32)$ & & & $(14.95)$ & $(-2.03)$ & $(2.01)$ \\
\hline \multirow[t]{2}{*}{ Sydney } & $3.66^{*}$ & 0.42 & 3.24 & \multirow[t]{2}{*}{29.77} & \multirow[t]{2}{*}{32.99} & $-3.22 * * *$ & $17.84 * * *$ & $21.50 * * *$ \\
\hline & $(1.90)$ & $(0.37)$ & (1.14) & & & $(-14.64)$ & $(-2.59)$ & $(3.08)$ \\
\hline \multirow[t]{2}{*}{ All } & $3.47 * *$ & 0.42 & 3.05 & \multirow[t]{2}{*}{36.65} & \multirow[t]{2}{*}{33.84} & $2.81 * * *$ & $-17.35 * * *$ & $20.82 * * *$ \\
\hline & $(2.01)$ & $(0.40)$ & $(1.18)$ & & & $(7.84)$ & $(-3.52)$ & $(4.21)$ \\
\hline
\end{tabular}


Table 3

\section{Local Performance by Local Bias}

Every month, funds are ranked by their fund weight in local stocks against the market weight in local stocks and placed into three groups, 1 with the lowest local stock weighting, 3 the highest. The table reports the average risk-adjusted return using the methodology of Fong, Gallagher and Lee (2007) of local (AlphaL), distant stocks (AlphaD) and the return difference $(\Delta \mathrm{AlphaL})$, fund weight in local stocks (WeightL), market weight and the weight difference ( $\Delta$ WeightL), valueweighted risk-adjusted returns of local stocks not held (Not HeldL) and its difference to the fund's locally held ( $\Delta$ Not HeldL). T-statistics are in parenthesis. $* * *, * * *$ denotes statistical significance at the 1,5 and $10 \%$ level.

\begin{tabular}{ccccccccc}
\hline $\begin{array}{c}\text { Local } \\
\text { Rank }\end{array}$ & AlphaL & AlphaD & $\Delta$ AlphaL & $\begin{array}{c}\text { WeightL } \\
(\%)\end{array}$ & $\begin{array}{c}\text { M. } \\
\text { Weight } \\
(\%)\end{array}$ & $\Delta$ WeightL & $\begin{array}{c}\text { Not } \\
\text { HeldL }\end{array}$ & $\begin{array}{c}\Delta \text { Not } \\
\text { HeldL }\end{array}$ \\
& 3.75 & 0.64 & 3.12 & 24.39 & 33.10 & $-8.71^{* * *}$ & $-9.21^{* * *}$ & $12.97 * * *$ \\
& $(1.77)$ & $(0.45)$ & $(1.02)$ & & & $(-37.60)$ & $(-2.76)$ & $(3.91)$ \\
2 & 3.54 & 0.61 & 2.93 & 32.26 & 32.86 & $-0.60^{* * *}$ & $-10.20^{* *}$ & $13.95^{* * *}$ \\
& $(1.70)$ & $(0.52)$ & $(1.01)$ & & & $(-2.78)$ & $(-2.20)$ & $(3.26)$ \\
3 & $2.98 *$ & -0.36 & 3.34 & 41.33 & 33.88 & $7.45^{* * *}$ & $-8.98^{* * *}$ & $11.96^{* * *}$ \\
& $(1.82)$ & $(-0.27)$ & $(1.32)$ & & & $(20.46)$ & $(-2.86)$ & $(3.53)$ \\
$3-1$ & -0.77 & -0.99 & 0.22 & & & & 0.24 & -1.01 \\
& $(-0.49)$ & $(-0.66)$ & $(0.10)$ & & & & $(0.09)$ & $(-0.33)$ \\
$3-2$ & -0.57 & -0.97 & 0.40 & & & & 1.73 & -2.41 \\
& $(-0.38)$ & $(-0.68)$ & $(0.18)$ & & & & $(0.40)$ & $(-0.52)$ \\
\hline
\end{tabular}




\section{Table 4}

\section{Performance by City and by Fund City}

Table reports the average risk-adjusted return, difference of fund weight to S\&P/ASX 300 weight and the difference of stocks held in a city less the value-weighted return of stocks not held ( $\Delta$ Not Held) for Melbourne, Sydney and Other funds. A stock is located in Melbourne or Sydney if its headquarters is located within $1 \mathrm{~km}$ of the city centre. T-statistics are in parenthesis. $* * *, * *, *$ denotes statistical significance at the 1,5 and $10 \%$ level.

\begin{tabular}{cccccccc}
\hline Fund City & City & Alpha & $\mathrm{T}$ & $\Delta$ Weight $(\%)$ & $\mathrm{T}$ & $\Delta$ Not Held & $\mathrm{T}$ \\
Melb. & Melb. & 1.47 & $(0.78)$ & $8.84^{* * *}$ & $(14.95)$ & $8.03 * *$ & $(2.01)$ \\
& Other & -3.35 & $(-1.23)$ & $-7.47 * * *$ & $(-16.8)$ & -1.89 & $(-0.47)$ \\
& Syd. & $3.99 * *$ & $(2.01)$ & $-1.37 * * *$ & $(-5.01)$ & $10.26 * * *$ & $(3.94)$ \\
\multirow{2}{*}{ Other } & Melb. & 0.50 & $(0.24)$ & -0.48 & $(-1.40)$ & 5.07 & $(1.13)$ \\
& Other & 0.46 & $(0.19)$ & $1.76^{* * *}$ & $(5.48)$ & 2.40 & $(0.68)$ \\
& Syd. & 2.72 & $(1.26)$ & $-1.28 * * *$ & $(-5.45)$ & 6.85 & $(1.79)$ \\
Syd. & Melb. & 1.17 & $(0.67)$ & $3.28^{* * *}$ & $(14.69)$ & $12.86^{* *}$ & $(2.45)$ \\
& Other & -0.19 & $(-0.09)$ & -0.06 & $(-0.21)$ & 3.50 & $(0.61)$ \\
& Syd. & $3.66^{*}$ & $(1.90)$ & $-3.22^{* * *}$ & $(-14.64)$ & $21.50^{* * *}$ & $(3.08)$ \\
All & Melb. & 1.18 & $(0.68)$ & $3.50^{* * *}$ & $(17.37)$ & $8.84 * *$ & $(2.38)$ \\
& Other & -0.31 & $(-0.15)$ & -0.41 & $(-1.50)$ & 1.69 & $(0.53)$ \\
& Syd. & $3.66^{*}$ & $(1.91)$ & $-3.09 * * *$ & $(-15.47)$ & $11.13 * * *$ & $(4.91)$ \\
\hline
\end{tabular}




\section{Table 5}

\section{City Fund Over-Weighting and Performance by Stock City and Stock Size}

Table reports the time-series value-weighted average fund weight position of city funds by stock city and stock size relative to index-weights of the S\&P/ASX 300 and alpha performance. 'Large Cap' is the largest 50 stocks by index weight, 'Mid Cap' the largest 51 to 100 stocks and 'Small Cap' is all other stocks in the index. Panel A reports average fund weight less market weights in stocks by city and size, Panel B alpha performance and Panel C alpha of stocks held less stocks not held. T-statistics are in parenthesis. $* * *, * * *$ denotes statistical significance at the 1, 5 and $10 \%$ level.

\begin{tabular}{|c|c|c|c|c|}
\hline \multicolumn{5}{|c|}{ Panel A. Fund Weight - Market Weight } \\
\hline Fund City & City & Large Cap (\%) & Mid Cap $(\%)$ & Small Cap (\%) \\
\hline \multirow[t]{6}{*}{ Melbourne } & Melbourne & $10.52 * * *$ & $-0.54 * * *$ & $-0.84 * * *$ \\
\hline & & $(16.36)$ & $(-12.85)$ & $(-18.27)$ \\
\hline & Other & $-1.42 * * *$ & $-2.06 * * *$ & $-3.95 * * *$ \\
\hline & & $(-7.2)$ & $(-7.03)$ & $(-18.51)$ \\
\hline & Sydney & $2.81 * * *$ & $-2.26 * * *$ & $-1.74 * * *$ \\
\hline & & $(12.61)$ & $(-22.37)$ & $(-24.04)$ \\
\hline \multirow[t]{6}{*}{ Other } & Melbourne & 0.58 & -0.06 & $1.37 * * *$ \\
\hline & & $(1.67)$ & $(-0.66)$ & $(3.95)$ \\
\hline & Other & -0.25 & $1.93 * * *$ & $-1.80 * * *$ \\
\hline & & $(-0.53)$ & $(8.62)$ & $(-5.44)$ \\
\hline & Sydney & $0.84 * * *$ & $-1.47 * * *$ & $-0.64 * * *$ \\
\hline & & $(2.87)$ & $(-7.88)$ & $(-6.30)$ \\
\hline \multirow[t]{6}{*}{ Sydney } & Melbourne & $3.58 * * *$ & $0.30 * * *$ & $-0.59 * * *$ \\
\hline & & $(14.44)$ & $(4.29)$ & $(-29.04)$ \\
\hline & Other & $-1.15 * * *$ & $1.70 * * *$ & $-0.53 * * *$ \\
\hline & & $(-7.53)$ & $(13.14)$ & $(-3.94)$ \\
\hline & Sydney & $-0.81 * * *$ & $-1.25 * * *$ & $-1.24 * * *$ \\
\hline & & $(-3.37)$ & $(-23.71)$ & $(-17.76)$ \\
\hline \multicolumn{5}{|c|}{ Panel B. Alpha by Stock Size and City } \\
\hline Fund City & City & Large Cap & Mid Cap & Small Cap \\
\hline \multirow[t]{6}{*}{ Melbourne } & Melbourne & 1.38 & -0.46 & 12.88 \\
\hline & & $(0.73)$ & $(-0.05)$ & $(0.79)$ \\
\hline & Other & -3.96 & -7.65 & $16.06^{* *}$ \\
\hline & & $(-1.27)$ & $(-1.16)$ & $(2.2)$ \\
\hline & Sydney & $3.65^{*}$ & 4.94 & 14.12 \\
\hline & & $(1.82)$ & $(0.87)$ & (1.68) \\
\hline \multirow[t]{2}{*}{ Other } & Melbourne & -0.02 & 5.52 & 13.11 \\
\hline & & $(-0.01)$ & $(0.55)$ & (1.09) \\
\hline
\end{tabular}




\begin{tabular}{|c|c|c|c|c|}
\hline & Other & $\begin{array}{c}-1.03 \\
(-0.33)\end{array}$ & $\begin{array}{c}5.01 \\
(1.13)\end{array}$ & $\begin{array}{c}6.48 \\
(0.76)\end{array}$ \\
\hline & Sydney & 3.78 & -12.39 & -2.88 \\
\hline & & $(1.76)$ & $(-1.66)$ & $(-0.29)$ \\
\hline \multirow[t]{6}{*}{ Sydney } & Melbourne & 0.88 & 1.17 & 11.36 \\
\hline & & $(0.5)$ & $(0.16)$ & (1.39) \\
\hline & Other & -1.21 & 2.17 & 2.04 \\
\hline & & $(-0.45)$ & $(0.72)$ & $(0.76)$ \\
\hline & Sydney & $4.78 * *$ & -3.94 & -6.01 \\
\hline & & $(2.32)$ & $(-0.79)$ & $(-0.98)$ \\
\hline
\end{tabular}

\begin{tabular}{|c|c|c|c|c|}
\hline Fund City & City & Large Cap (\%) & Mid Cap (\%) & Small Cap (\%) \\
\hline \multirow[t]{6}{*}{ Melbourne } & Melbourne & 12.71 & 8.94 & 14.35 \\
\hline & & $(1.29)$ & $(0.74)$ & $(0.85)$ \\
\hline & Other & -7.90 & -5.60 & $21.00 * * *$ \\
\hline & & $(-0.78)$ & $(-0.69)$ & $(2.66)$ \\
\hline & Sydney & 13.48 & $13.12 * *$ & $19.04 * *$ \\
\hline & & $(1.75)$ & $(2.01)$ & $(2.22)$ \\
\hline \multirow[t]{6}{*}{ Other } & Melbourne & 6.74 & 15.11 & 14.64 \\
\hline & & $(0.72)$ & (1.19) & $(1.16)$ \\
\hline & Other & 6.06 & 2.78 & 8.51 \\
\hline & & $(0.90)$ & $(0.38)$ & $(0.95)$ \\
\hline & Sydney & 1.26 & -3.09 & 2.23 \\
\hline & & $(0.16)$ & $(-0.35)$ & $(0.21)$ \\
\hline \multirow[t]{6}{*}{ Sydney } & Melbourne & -1.44 & 9.47 & $22.44 * *$ \\
\hline & & $(-0.35)$ & $(1.36)$ & $(2.27)$ \\
\hline & Other & 0.54 & -4.75 & 8.64 \\
\hline & & $(0.21)$ & $(-0.54)$ & $(1.40)$ \\
\hline & Sydney & 0.61 & 25.88 & 2.76 \\
\hline & & $(0.46)$ & $(1.64)$ & $(0.32)$ \\
\hline
\end{tabular}




\section{Table 6}

\section{Fund Style Performance by Book-to-Market Stocks}

Table reports time series value-weighted fund average annualised performance and weighting measures by city and fund style and by stock's book to market ratio for the period 1997-2001. Every month, stocks are sorted into five groups by book-to-market. BM Group 1 is the group of stocks with the lowest book-to-market (growth stocks) and Group 5 the highest (value stocks). A stock is a local stock if it is located $1 \mathrm{~km}$ to the fund's city. $\Delta$ AlphaL is the alpha of local stocks less the alpha of distant stocks held in the BM Group. $\triangle$ Not HeldL is the alpha of local stocks held less the value-weighted alpha of local stocks not held in the BM group. $\Delta \Delta$ Not Held is the difference of $\Delta$ Not Held and the alpha of distant stocks less the value-weighted alpha of distant stocks not held in the BM group. $\Delta$ WeightL is the fund weight in local stocks less the market weight of local stocks in that particular BM group. $\Delta \Delta$ Weight is the difference of $\Delta$ WeightL and the fund weight in distant stocks less the market weight of distant stocks in that BM group. ***, **,* denotes statistical significance at the 1,5 and $10 \%$ level.

\begin{tabular}{|c|c|c|c|c|c|}
\hline \multicolumn{6}{|c|}{ Melbourne GARP } \\
\hline BM Group & $\Delta$ AlphaL & $\Delta$ Not HeldL & $\Delta \Delta$ Not Held & $\Delta$ WeightL & $\Delta \Delta$ Weight \\
\hline 1 (Growth) & -0.63 & $23.51 *$ & $24.23 * * *$ & $-1.23 * *$ & 3.59 \\
\hline 2 & 0.21 & -2.99 & $-12.52 * * *$ & $4.36 * * *$ & 5.58 \\
\hline 3 & 1.00 & -1.18 & 0.79 & $1.70 * * *$ & 0.01 \\
\hline 4 & -0.23 & 4.63 & -5.14 & -0.12 & -0.50 \\
\hline 5 (Value) & -0.28 & $26.58 * * *$ & 24.8 & -0.16 & $0.43 * * *$ \\
\hline \multicolumn{6}{|c|}{ Melbourne Growth } \\
\hline BM Group & $\Delta$ AlphaL & $\Delta$ Not HeldL & $\Delta \Delta$ Not Held & $\Delta$ WeightL & $\Delta \Delta$ Weight \\
\hline 1 (Growth) & -0.43 & 5.97 & $10.59 * * *$ & 0.02 & -5.49 \\
\hline 2 & 0.70 & 8.50 & $10.92 * * *$ & $2.11 * * *$ & $-2.32 *$ \\
\hline 3 & 0.27 & -2.14 & $-6.51 * * *$ & -0.24 & 4.33 \\
\hline 4 & 0.00 & -1.46 & $-5.90 * * *$ & -0.11 & 4.60 \\
\hline 5 (Value) & -0.12 & -5.35 & $-4.76 * * *$ & -0.06 & 2.31 \\
\hline \multicolumn{6}{|c|}{ Melbourne Style Neutral } \\
\hline BM Group & $\Delta$ AlphaL & $\Delta$ Not HeldL & $\Delta \Delta$ Not Held & $\Delta$ WeightL & $\Delta \Delta$ Weight \\
\hline 1 (Growth) & $-1.16^{*}$ & $36.13 * * *$ & $34.57 * * *$ & $1.62 * * *$ & $3.30 * * *$ \\
\hline 2 & 1.23 & 1.06 & $3.77 * * *$ & $9.79 * * *$ & 11.78 \\
\hline 3 & -0.22 & 1.48 & $-4.30 * * *$ & $3.19 * * *$ & 6.01 \\
\hline 4 & $0.52 *$ & 6.57 & $5.62 * * *$ & $-0.7 * * *$ & 3.52 \\
\hline 5 (Value) & -0.05 & 0.87 & $-0.04 * * *$ & $-0.49 * * *$ & 2.23 \\
\hline \multicolumn{6}{|l|}{ Sydney GARP } \\
\hline BM Group & $\Delta$ AlphaL & $\Delta$ Not HeldL & $\Delta \Delta$ Not Held & $\Delta$ WeightL & $\Delta \Delta$ Weight \\
\hline 1 (Growth) & $1.04 *$ & 7.97 & -4.54 & $-0.34^{*}$ & 0.52 \\
\hline 2 & 0.56 & 4.88 & -5.49 & $1.42 * * *$ & -0.68 \\
\hline 3 & -0.02 & $16.62 * * *$ & $15.92 * * *$ & -0.20 & $-2.69 * *$ \\
\hline 4 & -0.27 & 3.35 & $2.78 * * *$ & $-3.62 * * *$ & -4.13 \\
\hline 5 (Value) & 0.07 & -1.11 & $-1.06 * * *$ & $-1.17 * * *$ & -0.84 \\
\hline
\end{tabular}


Sydney Growth

BM Group

1 (Growth)

$\Delta$ AlphaL $\quad \Delta$ Not HeldL

0.14

$-0.33$

$-0.36$

5 (Value)

0.00

Sydney Style Neutral

BM Group

1 (Growth)

2

3

4

5 (Value)

Sydney Value

BM Group

1 (Growth)

2

3

4

5 (Value)
$\Delta$ AlphaL $\quad \Delta$ Not HeldL

$-0.19$

0.47

$-0.40$

$-0.27$

0.52

$\triangle$ AlphaL

0.50

0.44

$-0.32$

$-0.46$

0.19
$-11.64$

12.57

$14.40^{* *}$

12.98

7.08
$\Delta$ Not HeldL

6.52

5.96

9.64

$6.10 *$

$-3.57$

$$
-2.47
$$

12.31

8.16

5.91

$-0.75$

$\Delta \Delta$ Not Held

$-9.35$

$11.64 * * *$

$3.34 * * *$

$3.65^{* * *}$

$-4.56$

$\Delta \Delta$ Not Held

$$
-6.00^{* * *}
$$

5.09

$5.21 * * *$

9.91

$-8.22^{* * *}$
$\Delta \Delta$ Not Held $\quad \Delta$ WeightL

$-4.83 * * * \quad-3.31 * * *$

$-9.37 * * * \quad-1.87^{* * *}$

$4.51 * * *$

$-0.40 * * *$

$-7.46$

$0.83 * *$

$-1.33^{* * *}$

$-0.71 * * *$
$\Delta$ WeightL

$6.07 * * *$

$3.77 * * *$

$-0.70 * * *$

$-4.64 * * *$

$-2.14 * * *$

$\Delta$ WeightL

$-1.52^{* * *}$

$0.83 * * *$

$-1.63 * * *$

$-0.27$

0.51
$\Delta \Delta$ Weight

$-0.28$

3.22

3.88

$-1.96$

$-0.12$ 


\section{Table 7}

\section{Fund City Performance in Financial Stocks}

Table reports time series value-weighted fund average annualised performance and weighting measures by fund city for Banking and Finance (Industry Code 16) and Financial Services (Industry Code 19) stocks for the period 1997-2001. A stock is a local stock if it is located $1 \mathrm{~km}$ to the fund's city. AlphaL is the alpha of local stocks. $\Delta$ AlphaL is the alpha of local stocks less the alpha of distant stocks held in the industry group. $\Delta$ WeightL is the fund weight in local stocks less the market weight of local stocks in that particular industry group. $\Delta \Delta$ Weight is the difference of $\Delta \mathrm{WeightL}$ and the fund weight in distant stocks less the market weight of distant stocks in that industry group. $* * *, * * *$ denotes statistical significance at the 1,5 and $10 \%$ level.

Banking and Finance Stocks (Industry Code 16)

$\begin{array}{ccccc}\text { Fund City } & \text { AlphaL } & \Delta \text { AlphaL } & \Delta \text { WeightL } & \Delta \Delta \text { Weight } \\ \text { Melbourne } & 3.10 & -5.64 & 7.08^{* * *} & 7.27^{* * *} \\ & (1.39) & (-1.24) & (21.45) & (16.10) \\ \text { Other } & 9.87^{* *} & 5.51 & -0.26^{* *} & -1.25^{* * *} \\ & (2.06) & (1.09) & (-2.14) & (-6.17) \\ \text { Sydney } & 7.20^{* * *} & -0.64 & 0.85^{* * *} & -0.86^{* * *} \\ & (3.06) & (-0.18) & (11.40) & (-3.56)\end{array}$

Financial Services Stocks (Industry Code 19)

\begin{tabular}{clclc} 
Fund City & AlphaL & $\Delta$ AlphaL & $\Delta$ WeightL & $\Delta \Delta$ Weight \\
Melbourne & -9.86 & -6.17 & $-0.13^{* * *}$ & $0.27^{* * *}$ \\
& $(-1.11)$ & $(-0.91)$ & $(-6.04)$ & $(10.84)$ \\
Other & $29.82^{* * *}$ & 3.43 & $-0.20^{* * *}$ & $-0.3^{* * *}$ \\
& $(2.70)$ & $(0.56)$ & $(-4.00)$ & $(-5.49)$ \\
Sydney & -0.17 & -2.85 & $-0.08^{* * *}$ & $0.26^{* * *}$ \\
& $(-0.03)$ & $(-0.29)$ & $(-6.35)$ & $(7.71)$ \\
\hline
\end{tabular}




\section{Table 8}

\section{Word-of-Mouth Effect}

Table reports OLS coefficient estimates and coefficient differences for the following model:

$$
\Delta h_{j, k, l, t}^{i}=\alpha_{c} \Delta H_{c, x k, t}^{i}+\beta_{c, t}^{i} * \Delta H_{c, t}+\gamma_{c} * \Delta H_{r, t}^{i}+\varepsilon_{j, k, l, t}^{i}
$$

Model estimates are made for Melbourne and Sydney funds and by where the stock is located. Panel A reports coefficients for the above model, Panel B for the above model and also three monthly lags for each of the independent variables. 'Own-Other', tests the null hypothesis the Own City coefficient less the Other City and Other Funds coefficients is statistically different to zero. 'Own-Other $1 \mathrm{Lag}$ ' tests for the first month lag coefficient differences and 'Own-Other 3 Lags Differential' for all three lags. T-statistics are in parenthesis, P-values in square brackets. $* * *, * *, *$ denotes statistical significance at the 1,5 and $10 \%$ level.

\begin{tabular}{|c|c|c|c|c|c|}
\hline \multicolumn{6}{|c|}{ Panel A. Contemporaneous Model } \\
\hline Fund City & Stock City & Own City & Other City & Other Funds & Own-Other \\
\hline \multirow[t]{2}{*}{ Melbourne } & \multirow[t]{2}{*}{ Melbourne } & $0.1418 * * *$ & $0.3695 * * *$ & $0.2284 * * *$ & $-0.4561 * * *$ \\
\hline & & $(4.4513)$ & $(5.371)$ & $(4.1137)$ & $\lceil<0.0001\rceil$ \\
\hline \multirow[t]{2}{*}{ Melbourne } & \multirow[t]{2}{*}{ Other } & $0.0737 * * *$ & $0.2856^{* * *}$ & 00522 & $-0.2641 * * *$ \\
\hline & & $(2.5282)$ & $(5.584)$ & $(1.6437)$ & $\lceil<0.0001\rceil$ \\
\hline \multirow[t]{2}{*}{ Melbourne } & \multirow[t]{2}{*}{ Sydney } & $0.1004 * * *$ & $0.2237^{* * *}$ & $0.0914 * *$ & $-0.2147 * * *$ \\
\hline & & $(2.9928)$ & $(4.8723)$ & $(2.4551)$ & $\lceil 0.0025\rceil$ \\
\hline \multirow[t]{2}{*}{ Sydney } & \multirow[t]{2}{*}{ Melbourne } & $0.1800^{* * *}$ & $0.0996^{* * *}$ & \multirow{2}{*}{$\begin{array}{l}0.0508^{* *} \\
(2.2953)\end{array}$} & 0.0296 \\
\hline & & $(6.6251)$ & $(5.8244)$ & & $\lceil 0.4708\rceil$ \\
\hline \multirow[t]{2}{*}{ Sydney } & \multirow[t]{2}{*}{ Other } & 0.0087 & $0.0790 * * *$ & \multirow{2}{*}{$\begin{array}{l}0.0679 * * * \\
(5.1538)\end{array}$} & $-0.1382 * * *$ \\
\hline & & $(0.6466)$ & $(6.167)$ & & $\lceil<.0001\rceil$ \\
\hline \multirow[t]{2}{*}{ Sydney } & \multirow[t]{2}{*}{ Sydney } & $0.1602 * * *$ & $0.1050^{* * *}$ & \multirow{2}{*}{$\begin{array}{l}0.0833^{* * *} \\
(4.0009)\end{array}$} & -0.0281 \\
\hline & & $(7.2731)$ & $(5.0918)$ & & $\lceil 0.4682\rceil$ \\
\hline \multicolumn{6}{|c|}{ Panel B. Contemporaneous Model with 3 Lags } \\
\hline Fund City & Stock City & Own-Other & Own-Other 1 Lag & \multicolumn{2}{|c|}{ Own-Other 3 Lags } \\
\hline \multirow[t]{2}{*}{ Melbourne } & \multirow[t]{2}{*}{ Melbourne } & $-0.4626 * * *$ & $0.1707 *$ & \multicolumn{2}{|c|}{0.1397} \\
\hline & & {$[<.0001]$} & {$[0.0905]$} & \multicolumn{2}{|c|}{ [0.3600] } \\
\hline \multirow[t]{2}{*}{ Melbourne } & \multirow[t]{2}{*}{ Other } & $-0.2773 * * *$ & 0.0552 & & 0.1585 \\
\hline & & {$[<.0001]$} & [0.4002] & & $0.1582]$ \\
\hline \multirow[t]{2}{*}{ Melbourne } & \multirow[t]{2}{*}{ Sydney } & $-0.2601 * * *$ & -0.0341 & & $0.2053^{*}$ \\
\hline & & {$[<0.0003]$} & {$[0.6272]$} & & $0.0861]$ \\
\hline Sydney & Melbourne & -0.0207 & $0.1645^{* * *}$ & & $0.1713^{* * *}$ \\
\hline & & {$[0.6167]$} & {$[<0.0001]$} & & $0.0084]$ \\
\hline Sydney & Other & $-0.1430 * * *$ & 0.0111 & & 0.0092 \\
\hline & & {$[<0.0001]$} & {$[0.6465]$} & & $0.8828]$ \\
\hline Sydney & Sydney & $-0.0663^{*}$ & 0.0501 & & $0.1159 *$ \\
\hline & & [0.0919] & [0.2237] & & $0.0853]$ \\
\hline
\end{tabular}

